\title{
DEVELOPING LEARNING COMMUNITY IN ONLINE ASYNCHRONOUS COLLEGE COURSES: THE ROLE OF TEACHING PRESENCE
}

\section{Peter Shea}

Department of Educational Theory and Practice

and College of Computing and Information

University at Albany, State University of New York

Chun Sau Li

School of Education

University at Albany, State University of New York

\author{
Karen Swan
}

Research Center for Educational Technology

Kent State University

Alexandra Pickett

SUNY Learning Network

State University of New York

\begin{abstract}
This paper builds on the model we have developed for creating quality online learning environments for higher education. In that model we argue that college-level online learning needs to reflect what we know about learning in general, what we understand about learning in higher-education contexts, and our emerging knowledge of learning in largely asynchronous online environments. Components of the model include a focus on learner roles, knowledge building, assessment, community, and various forms of "presence." In this paper we focus on two components-teaching presence and community-and review the rationale and benefits for an emphasis on community in online learning environments. We argue that learning is social in nature and that online learning environments can be designed to reflect and leverage the social nature of learning. We suggest that previous research points to the critical role that community can play in building and sustaining productive learning and that teaching presence, defined as the core roles of the online instructor, is among the most promising mechanism for developing online learning community. We present a multi-institutional study of 2,036 students across thirty-two different colleges that supports this claim and provides insight into the relationship between online learning community and teaching presence. Factor and regression analysis indicate a significant link between students' sense of learning community and their recognition of effective instructional design and directed facilitation on the part of their course instructors - and that student gender plays a small role in sense of learning community. We conclude with recommendations for online course design, pedagogy, and future research.
\end{abstract}

\section{KEYWORDS}

Online Teaching, Teaching Presence, Class Community, Social Learning, Learning Community

\section{INTRODUCTION}

Learning environments that are designed to leverage theoretically derived and research-based principles of good practice emphasize the critical role that students play in succeeding in their academic endeavors. Such learner-centered design reflects our current understanding of the social nature of learning and the importance of community in promoting learning. It is widely agreed that learning is, in some fundamental sense, social in nature [1]. Although wide diversity exists in social learning frameworks, common themes can be identifiedamong others, that learning frequently takes place between pairs or among groups of individuals, in cooperative or collaborative settings, and/or in communities or communities of practice [2-5]. 
Community has been defined in many ways, and various authors have focused on different elements of community, including trust, spirit, connectedness, belonging, membership, various forms of support, and the rich and productive milieu that communities of practice can engender for teaching and learning [4-9]. The benefits of community for learning have been documented by a number of authors. Rovai [7], for example, presents evidence suggesting a strong sense of community is essential in higher education learning environments. He asserts that community helps reduce feelings of isolation associated by some authors with distance and online learning [10,11]. A strong sense of community is also beneficial in reducing student "burnout" associated with higher attrition levels in distance learning [12]. Community membership promotes the likelihood of student support and information flow, commitment to group goals, cooperation among members, and satisfaction with group processes and efforts [6, 13-15]. The Community of Inquiry Model [16], of which teaching presence is one component, is founded on the importance of community to learning.

Previous research indicates that an important association exists between teacher behaviors and the development of virtual learning communities in online courses [7]. Shea et al. [17], for example, found significant differences in perceived learning between college students reporting varying levels of interaction with their instructors. Students who reported high levels of interaction with their instructors also reported higher levels of learning from them. Jiang and Ting [18] and Swan and Shea [19] reported a strong correlation between college student perceptions of learning and their perceived interactions with instructors. Richardson and Swan [20] reported a significant correlation between student satisfaction with their college instructors and their perceived learning online. In a review of faculty roles, Dzuiban, Shea, and Arbaugh [21] concluded that all paradigms of effective online teaching in higher education assert or imply that good online professors facilitate high levels of interaction with and between students.

Swan and Shea [19] also reported that students' perceptions of learning and interaction are accurate, at least concerning instructor activity. For example, they cite that Jiang and Ting [18] concluded that perceived learning and perceived interaction with professors were correlated to the actual average numbers of responses per student that instructors made. Swan et al. [22] also found a correlation between students' perceived interaction with their professors and the actual frequency of instructor participation in online course discussions. Furthermore, Picciano [23] reported that professors' actual activity in online education courses was related to students' perceived learning from them.

Interaction is necessary, but it is not sufficient to create a productive learning community. Others working in this area have focused more specifically on the development of such environments. Brown [24], for example, identified six causal conditions leading to the development of community among students in three online graduate school courses. These are (1) expected behaviors are modeled by the instructor; (2) sufficient time is available for online discussions and interaction; (3) similarities are identified between online participants; (4) a personal or academic need to be part of a community exists on the part of the participants; (5) a high priority is placed on the online course and interaction; and (6) participants are engaged in the course and course dialogue. Brown identifies three levels of community, indicating that an intermediate level developed after student participated in an extended and meaningful threaded discussion in which their ideas were accepted and considered worthy of further discussion. Although Brown asserts that the highest levels of community appear to require participation in multiple online courses and out-ofcourse or face-to-face communication, online instructors still have significant influence or control over the majority of the conditions leading to intermediate levels of community.

From the foregoing discussion, one can hypothesize an important relationship between instructor's online behaviors, the establishment of community, and the ultimate effectiveness of higher education online learning environments. These findings indicate the importance to students of interactions with their 
instructors and suggest the importance of instructors in the development of a sense of virtual community. However, as noted previously [19], specific connections between identifiable instructor activities and/or between student interactions with their instructors and the development of community have yet to be documented across a broad array of courses, programs, and institutions. This paper attempts to address this gap by examining instructor behaviors that support the development of learning community with a large and diverse sample of students, instructors, courses, and institutions.

Given the myriad learning benefits associated with a strong sense of community, we believe it is productive to attempt to determine how instructor behaviors may contribute to the development of community in online environments. We believe that effective teaching presence has the potential to create learning environments in which the benefits of online community may more easily be realized.

The remainder of this paper will describe a study designed to assess the relationship between students' perceptions of teaching presence and their sense of community, as well as levels of interaction, satisfaction, and learning in a multi-institution online setting. This research builds on previous studies [17, $25,26]$ assessing teaching presence, satisfaction, and learning in the SUNY Learning Network (SLN) the online, asynchronous learning environment of the State University of New York. We begin with a more detailed description of teaching presence in the next section.

\section{TEACHING PRESENCE}

In the model of critical thinking and practical inquiry proposed by Garrison and his colleagues [16], three overlapping lenses - cognitive presence, social presence, and teaching presence-provide mutual support to create a framework in which interaction in an asynchronous online educational experience may be assessed. The model seeks to explain how to best analyze and ultimately promote higher order learningthe cognitive and social processes associated with worthwhile and meaningful educational experiences-in computer-mediated, largely text-based environments such as the SUNY Learning Network. Teaching presence is a critical component of the model [26] for high-quality online learning environments that we are developing through our research in asynchronous learning networks. This model attempts to integrate and investigate what is known about learning generally [1] with research on learning in higher education $[27,28]$ and more recent understanding of learning in largely text-based online learning environments [16]. A central component of the model is a focus on community. The study outlined here attempts to investigate the link between teaching presence, community, and learning, all of which are further defined below.

Anderson and his colleagues [29] refer to teaching presence as "the design, facilitation, and direction of cognitive and social processes for the realization of personally meaningful and educationally worthwhile learning outcomes.” In their model, teaching presence has three components: instructional design and organization, facilitating discourse, and direct instruction. These categories align well with others identified by researchers working on the roles of instructors in online environments [30]. Under the category instructional design and organization, the authors include:

- setting curriculum

- designing methods

- establishing time parameters

- utilizing the medium effectively

- establishing netiquette 
Another component of teaching presence in the Anderson model is facilitating productive discourse. The task of facilitating discourse is necessary to maintain learner engagement and refers to "focused and sustained deliberation that marks learning in a community of inquiry" [29]. The authors provide indicators of the activity of facilitating discourse, which include:

- identifying areas of agreement and disagreement

- seeking to reach consensus and understanding

- encouraging, acknowledging, and reinforcing student contributions

- $\quad$ setting the climate for learning

- drawing in participants and prompting discussion

- $\quad$ assessing the efficacy of the process

Anderson et al. [29] also include indicators of direct instruction in their framework for the analysis of teaching presence. These indicators include:

- presenting content and questions

- focusing the discussion on specific issues

- summarizing discussion

- confirming understanding

- diagnosing misperceptions

- injecting knowledge from diverse sources

- responding to technical concerns

In two previous studies of teaching presence [17, 31] we found significant correlations between student's reports of high levels of these behaviors - on the part of both faculty and students - and students' degrees of satisfaction and learning in their courses. In addition, students reported higher levels of teaching presence, learning, and satisfaction in courses in which their instructors were trained and supported to establish teaching presence in effective ways. In the study outlined here, we again assessed student perceptions of teaching presence and also their perceptions of community, our aim being to understand the connection between teaching presence and the development of community.

\section{PARTICIPANTS}

Study participants consisted of 2,036 students studying in the summer 2004 semester at thirty-two State University of New York colleges in the SUNY Learning Network (SLN). Twenty-one of the institutions were community colleges, reflecting the overall proportion of community colleges to four-year institutions in SLN. In all, approximately 20\%, or 2,181, of the 10,907 students in the total summer 2004 student group were randomly presented the option of taking the survey when they logged in to their courses. The 2,036 students who responded to the survey indicate a response rate of approximately $93 \%$. Because some students took more than one course, 2,314 evaluation questionnaires were collected. Represented in the sample were 470 instructors and 581 courses.

Presented in Table 1 are demographic data, which is collected by the SUNY Learning Network when a student registers for an account. It is conceivable that these demographic variables could play a role in the formation of community, and therefore they were included in subsequent analysis. For example, in assessing the development of community, one course-factor demographic of interest might be the duration of the course in days, which was sorted into two categories: less than or equal to 65 days (51.3\%), and 
more than 65 days (48.7\%). If community development depends on interactions engaged in over time, then course duration may play a role.

\begin{tabular}{|c|c|c|}
\hline & $\mathrm{n}$ & $\%$ \\
\hline \multicolumn{3}{|l|}{ Gender } \\
\hline 1 Female & 1,689 & 73.0 \\
\hline 2 Male & 625 & 27.0 \\
\hline \multicolumn{3}{|l|}{ Age } \\
\hline $115-25$ & 916 & 39.6 \\
\hline $226-35$ & 640 & 27.7 \\
\hline $336-45$ & 506 & 21.9 \\
\hline $446-55$ & 217 & 9.4 \\
\hline $556-65$ & 34 & 1.5 \\
\hline $665+$ & 1 & .0 \\
\hline \multicolumn{3}{|l|}{ Registration status } \\
\hline 1 Full time & 1,010 & 43.6 \\
\hline 2 Part Time & 1,304 & 56.4 \\
\hline \multicolumn{3}{|l|}{ Employment Status } \\
\hline 1 Part-time & 609 & 26.3 \\
\hline 2 Full-time & 1,268 & 54.8 \\
\hline 3 Not employed & 437 & 18.9 \\
\hline \multicolumn{3}{|l|}{ Distance from campus } \\
\hline 1 On campus & 23 & 1.0 \\
\hline 2 Less than 30 minutes & 852 & 36.8 \\
\hline 330 minutes to 1 hour & 510 & 22.0 \\
\hline 41 hour to 2 hours & 292 & 12.6 \\
\hline 5 More than 2 hours & 637 & 27.5 \\
\hline \multicolumn{3}{|l|}{ Modem type } \\
\hline 128.8 & 43 & 1.9 \\
\hline 233.6 & 14 & 0.6 \\
\hline 356 & 372 & 16.1 \\
\hline 4 Cable Modem & 948 & 41.0 \\
\hline 5 LAN & 193 & 8.3 \\
\hline 6 DSL & 333 & 14.4 \\
\hline $7 \mathrm{ISDN}$ & 5 & 0.2 \\
\hline 8 Missing/Other/don’t know & 406 & 17.5 \\
\hline \multicolumn{3}{|l|}{ Why Online } \\
\hline 1 Conflict with personal schedule & 820 & 35.4 \\
\hline $\begin{array}{l}2 \text { Course not offered on campus/ } \\
\text { schedule conflict }\end{array}$ & 412 & 17.8 \\
\hline 3 Distance or lack of transportation & 378 & 16.3 \\
\hline
\end{tabular}


Developing Learning Community in Online Asynchronous College Courses: The Role of Teaching Presence

4 Family responsibilities

5 Interest in technology/internet

6 Other

Duration of course in days

$1 \leq 65$

1,186
1,128

19.1

3.2

8.2

190

51.3

48.7

Table 1. Demographic Information of the Respondents $(\mathrm{N}=2,314)$

Each of these demographics for the sample of respondents was also compared to the demographics for the whole population (see Appendix A) and demonstrates a close correlation to the overall response patterns for all students in the summer 2004 cohort. In the next section we discuss the instrument developed for the study.

\section{INSTRUMENTATION}

Participants responded to a forty-two-item survey (Appendix B) designed to measure students' perceptions of both teaching presence and learning community. The teaching presence portion of the survey was developed in consultation with Anderson, one of the authors of the teaching presence model used in this research. This section of the survey contained seventeen items to assess instructional design and organization, facilitation of discourse, and direct instruction. The scale assessing instructional design and organization has six items that reflect the setting of curriculum, the design of methods, establishment of time parameters, effective utilization of the medium, and the establishment of netiquette. The facilitationof-discourse section contained six items assessing the professor's proficiency in identifying areas of agreement and disagreement; seeking to reach consensus and understanding; encouraging, acknowledging, and reinforcing student contributions; setting the climate for learning; drawing in participants and prompting discussion; and assessing the efficacy of the instructional process. The direct-instruction section has five items assessing the professor's proficiency in presenting content and questions, focusing the discussion on specific issues, confirming understanding, diagnosing misperceptions, and injecting knowledge from diverse sources. The rating of the teaching presence components was on a five-point Likert-type scale, from strongly disagree $=0$, disagree $=1$, neutral $=2$, agree $=3$, to strongly agree $=4$. One goal of our research was to determine the validity and reliability of this teaching-presence instrument, as we propose to use this construct as the independent variable in this study.

To assess students' sense of learning and community, we used Rovai's Classroom Community Scale [7, 8], which we will refer to as a measure of learning community - the dependent measure for this study. The Classroom Community Scale's twenty items, which are items 4 through 23 in the instrument included in Appendix B, measure learning community through two subscales, connectedness and learning. The connectedness subscale reflects respondents' feelings regarding cohesion, spirit, trust, and interdependence; the learning subscale reflects the degree to which respondents shared educational goals and benefits through their interaction with other course participants. We believe that the instrument is a good measure of the characteristics of a learning community-i.e., students' sense of trust, belonging, and mutual support in the pursuit of shared educational goals.

Additional survey items asked about students' levels of learning and satisfaction in the course and collected demographic data. We considered it likely that other demographic variables, such as age, gender, and reason for taking courses online, would have an impact on a student's sense of connectedness and community. For example, previous research on the relationship between age and social isolation [32, 
33] has found higher levels of social isolation with increases in age, thus suggesting possible variations in sense of community or connectedness by age. Similar differences have been found in regard to gender [34, 35, 36, 37], with females in general less socially isolated than males, suggesting possible variations in scores for sense of community or connectedness by gender. We also believed that a respondent's reason for taking a course, physical distance from campus, and employment status would reflect underlying differences in sense of community; distance from campus and interest in online learning, for example, may be indicators of isolation. Finally, we believed that the duration of the course could have an impact on a participant's sense of community - for example, longer courses may provide greater opportunity for creating bonds. These variables were therefore included in the analysis.

\section{PROCEDURES}

The survey was completed online by a sample of participants enrolled in the summer 2004 semester. The survey was programmed to appear at random two weeks before the end date of the course when students in the sample logged in. Students in the sample were contacted via email three times by the program administrators with requests to complete the survey when it appeared. The program administrators also enlisted the assistance of the faculty teaching courses during this period, asking them to encourage their students to complete the survey. A certain degree of caution needs to be taken in interpreting the results of this survey in light of the fact that only students who completed their courses were included in the sample-i.e., the levels of satisfaction reported here are for students who did not drop out and may be higher than those for non-completers.

\section{RESULTS}

\section{A. Factor Analysis}

The item correlation matrix for teaching presence is presented in Table 2. As can be seen, the coefficients were greater than .30, which indicates acceptable use of factor analysis [38]. All correlations were significant at the 0.01 level.

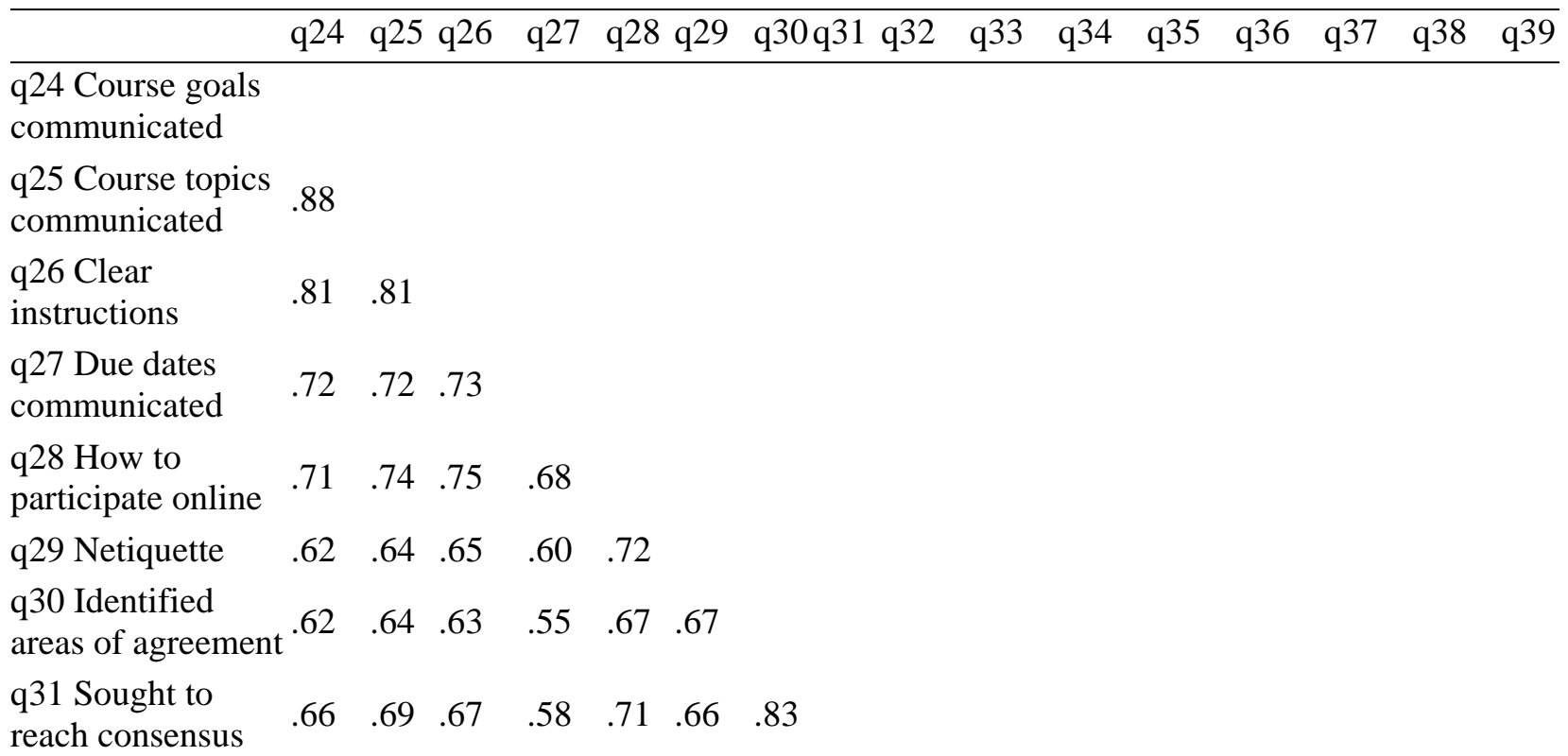


Developing Learning Community in Online Asynchronous College Courses:

The Role of Teaching Presence

\begin{tabular}{|c|c|c|c|c|c|c|c|c|c|c|c|c|c|c|c|}
\hline $\begin{array}{l}\text { q32 Reinforced } \\
\text { student } \\
\text { contributions }\end{array}$ & .61 & .63 & .62 & .56 & .66 & .61 & .73. & & & & & & & & \\
\hline $\begin{array}{l}\text { q33 Set climate for } \\
\text { learning }\end{array}$ & r.60 & .62 & .62 & .53 & .66 & .63 & .72 .76 & .76 & & & & & & & \\
\hline $\begin{array}{l}\text { q34 Drew in } \\
\text { participants }\end{array}$ & .59 & .60 & .59 & .51 & .65 & .61 & .75.77 & .76 & .79 & & & & & & \\
\hline $\begin{array}{l}\text { q35 Kept students } \\
\text { on task }\end{array}$ & .64 & .66 & .65 & .58 & .69 & .65 & .78. & .76 & .76 & .84 & & & & & \\
\hline $\begin{array}{l}\text { q36 Presented } \\
\text { content and } \\
\text { questions }\end{array}$ & .66 & .69 & .67 & .57 & .68 & .62 & .72 .78 & .68 & .70 & .70 & .76 & & & & \\
\hline $\begin{array}{l}\text { q37 Focused the } \\
\text { discussion }\end{array}$ & .64 & .66 & .64 & .55 & .68 & .63 & .74 .79 & .71 & .74 & .75 & .78 & .83 & & & \\
\hline $\begin{array}{l}\text { q38 Confirmed } \\
\text { understanding }\end{array}$ & .65 & .67 & .67 & .58 & .70 & .61 & .76.80 & .78 & .72 & .74 & .77 & .75 & .76 & & \\
\hline $\begin{array}{l}\text { q39 Diagnosed } \\
\text { misperceptions }\end{array}$ & .61 & .63 & .61 & .55 & .65 & .61 & .74 .78 & .72 & .71 & .71 & .75 & .73 & .73 & .82 & \\
\hline $\begin{array}{l}\text { q40 Injected } \\
\text { knowledge }\end{array}$ & .59 & .62 & .60 & .54 & .67 & .60 & .68.71 & .65 & .69 & .68 & .70 & .72 & .71 & .71 & .72 \\
\hline
\end{tabular}

Table 2. Item Correlations

Maximum likelihood factor analysis with direct oblique rotation was applied to examine the hypothesized elements of teaching presence (instructional design and organization, facilitating discourse, and direct instruction) and to determine the dimensionality of the components. Delta was zero. The Kaiser-MeyerOlkin (KMO) measure of sampling adequacy was .97, indicating that none of the teaching presence items violated the facto analysis assumption in regards to multicollinearity. Bartlett's test of sphericity resulted in a chi-square of 43814.76 ( $\mathrm{p}<0.001$ ), which is evidence that the data are approximately multivariate normal and acceptable for factor analysis. The following criteria were utilized to decide how many factors should be extracted: the scree plot, the Kaiser-Gutman rule, and the interpretability of the solution. The initial factor analysis did not confirm an interpretable three-factor solution, especially in regard to the direct instruction component. However, the scree plot and Kaiser-Gutman criteria indicated that two factors could be interpreted—both factors had eigenvalues greater than 1.00.

The analysis was rerun using two factors and the maximum likelihood method with oblique rotation. The resulting pattern matrix is presented in Table 3. A two-factor solution was highly interpretable, with items loaded high on one factor and low on the other. The analysis reveals that $74.37 \%$ of the variability of the teaching presence construct can be accounted for. The two factors were instructional design and organization, and directed facilitation-the latter a revised category incorporating elements of both discourse facilitation and direct instruction.

\begin{tabular}{lcc}
\hline & $\begin{array}{c}\text { Directed } \\
\text { Facilitation }\end{array}$ & $\begin{array}{c}\text { Instructional Design \& } \\
\text { Organization }\end{array}$ \\
\hline Drew in participants & $\mathbf{. 9 9}$ & .14 \\
Kept students on task & $\mathbf{. 9 2}$ & .02 \\
Set climate for learning & $\mathbf{. 8 8}$ & .03
\end{tabular}


Identified areas of agreement

Sought to reach consensus

Diagnosed misperceptions

Focused the discussion

Reinforced student contributions

Confirmed understanding

Injected knowledge

Presented content and questions

Netiquette

Course goals were communicated

Course topics were clear

Clear instructions were provided

Due dates were clear

How to participate online
.88

.87

.86

.84

.83

.83

.74

.72

.45

$-.06$

$-.01$

.08

.04

.38
.01

$-.04$

.01

$-.04$

$-.02$

$-.07$

$-.08$

$-.16$

$-.35$

$-.97$

.94

$-.82$

$-.76$

$-.51$

Table 3. Pattern Matrix

\section{B. Reliability}

Reliability analysis was applied to examine the internal consistency of the learning community measure and the teaching presence scales. Results are presented in Table 4 indicating that the learning community scale and its subscales_connectedness and learning - were satisfactory (measures for Cronbach's alpha were over .90). The reliability coefficients of the teaching presence scale and its componentsinstructional design and organization, and directed facilitation—were .94 and .97 respectively.

\begin{tabular}{cc}
\hline & Cronbach's Alpha \\
\hline Learning Community Scale & .94 \\
Connectedness & .91 \\
Learning & .90 \\
Teaching Presence Scale & .97 \\
Instructional Design and Organization & .94 \\
Directed Facilitation & .97 \\
\hline
\end{tabular}

Table 4. Reliabilities Coefficients of Learning Community Scale (Connectedness and Learning) and Teaching Presence (Instructional Design \& Organization, and Directed Facilitation)

\section{Preliminary Analysis}

No missing values were found in the learning community and teaching presence measures. The scores on both measures were obtained by summing up the items. The means, standard deviations, and correlations among the learning community and the teaching presence factors are presented in Table 5. The mean for total learning community scale was 53.53 out of a possible 80 with a standard deviation of 12.53; the mean of the connectedness subscale was 24.14 out of a possible score of 40 with a standard deviation of 6.70, the mean of the learning subscale was 29.22 out of a possible 40 with a standard deviation of 6.93. The mean overall score for teaching presence was 52.62 (with a maximum score of 68) with a standard deviation of 13.75, the mean score for instructional design and organization was 16.64 (with a maximum score of 20) with a standard deviation of 3.91, of and the mean score for directed facilitation was 35.99 
(with a maximum score of 48) with a standard deviation of 10.40 .

Pearson correlation analysis was applied to examine the relationships between learning community and teaching presence. Results showed that significant and positive correlations were found between the teaching presence measures and total learning community measures; the correlation coefficient was .76. It was found that teaching presence has a higher correlation with perceived learning (.80) than with sense of connectedness (.60). The intercorrelation among the learning community components was moderate, with a coefficient of .69, whereas the intercorrelation among the teaching presence components was high, with a coefficient of .82 .

\begin{tabular}{|c|c|c|c|c|c|c|c|}
\hline & Mean & SD & TCC & $\mathrm{CC}$ & $\mathrm{LC}$ & $\mathrm{TP}$ & IDO \\
\hline Total Learning Community (TLC) & 53.35 & 12.53 & & & & & \\
\hline Connectedness & 24.14 & 6.70 & $* * * .92$ & & & & \\
\hline Learning & 29.22 & 6.93 & $* * * .92$ & $* * * .69$ & & & \\
\hline Teaching Presence (TP) & 52.62 & 13.75 & $* * * .76$ & $* * * 60$ & $* * * .80$ & & \\
\hline Instructional Design and Organization (IDO) & 16.64 & 3.91 & $* * * .66$ & $* * * .48$ & $* * * .73$ & $* * * .90$ & \\
\hline Directed Facilitation (DF) & 35.99 & 9.73 & $* * * .76$ & $* * * .61$ & $* * * .78$ & $* * * .99$ & $* * * .81$ \\
\hline
\end{tabular}

Table 5. Mean, Standard Deviation, and Correlation Coefficients of the Learning Community Scale and Teaching Presence Measures (Instructional Design, Facilitating Discourse, and Direct Instruction)

\section{Multiple Regression Analysis}

A multiple regression analysis was applied to examine the relationship between the learning community measures, the revised teaching presence construct, and demographic information. In the regression analysis, the dependent variable was total learning community as reflected by scores on the Classroom Community Scale. The independent variables were instructional design and organization, directed facilitation, and the demographic data that were converted to dummy values. The demographic data included gender, age, employment status, distance from campus, reason for taking courses online, registration status, and course duration. No violations were found in the assumptions of normality, linearity, and homoscedasticity of residuals. Twenty-five outliers were found based on the criteria of beyond \pm 3 standard deviations; these were removed, and thus 2289 cases were used in the present analysis.

Presented in Table 6 are the unstandardized betas (B), standard error (SE B) and standardized betas (Beta) of the independent variables. The results of the regression model were found to be significant, F (21, $2288)=183.13, p<.001$. The multiple correlation coefficient was .79, indicating that $63 \%$ of total variance of learning community could be accounted for by the revised construct of teaching presence and the demographic characteristic. The constructs instructional design and organization and directed facilitation significantly contributed to the learning community measures. It was found that gender was also a significant predictor of learning community, although other demographic data were not significant in the present study.

\begin{tabular}{lccc} 
& B & SE B & Beta \\
\hline (Constant) & $* * * 23.77$ & 7.90 & \\
Instructional Design and Organization & $* * * .44$ & .07 & .14 \\
Directed Facilitation & $* * * .81$ & .03 & .67
\end{tabular}




\begin{tabular}{lccc} 
Gender (1=female, 2=male) & $*-.82$ & .36 & -.03 \\
Registration Status & .58 & .37 & .02 \\
15-25 years old & -8.18 & 7.62 & -.32 \\
26-35 years old & -7.34 & 7.62 & -.26 \\
36-45 years old & -6.62 & 7.62 & -.22 \\
46-55 years old & -7.63 & 7.63 & -.18 \\
56-65 years old & -6.61 & 7.73 & -.06 \\
Part-time Employment & .35 & .50 & .01 \\
Full-time Employment & .71 & .46 & .03 \\
$<30$ minutes & .71 & 1.69 & .03 \\
More than 30 minutes and less than 1 hour & 1.04 & 1.70 & .03 \\
More than 1 hour and less than 2 hours & .87 & 1.73 & .02 \\
More than 2 hours & .54 & 1.70 & .02 \\
Distance or lack of transportation & .11 & .62 & .00 \\
Conflict with personal schedule & -.46 & .68 & -.01 \\
Course not offered & .26 & .69 & .01 \\
Family responsibilities & .28 & .68 & .01 \\
Personal interest in technology/internet & .06 & 1.06 & .00 \\
Course duration & -.22 & .33 & -.01 \\
\hline p $<$ *** $\mathrm{p}<.001$ & & &
\end{tabular}

Table 6. The Unstandardized Beta, Standard Error, and Standard Beta

All the insignificant predictors were excluded, and the regression model was run again. The independent variables used to predict the learning community measure were instructional design and organization, directed facilitation, and gender. Analysis of variance indicated that the results of the model were significant, $\mathrm{F}(3,2288)=1259.12, \mathrm{p}<.001$. The correlation coefficients among learning community, the two teaching presence components and gender, the unstandardized beta, standard error and standard beta of the regression model are presented in Table 7 . The multiple correlation coefficient was .79, indicating that $62 \%$ of total variance of learning community could be accounted for by instructional design and organization, directed facilitation, and gender. The standardized coefficients were .14, .67, and -.03, which implied that directed facilitation has a greater contribution in predicting learning community and that female participants tend to have a slightly higher sense of learning community.

\begin{tabular}{lcccccc} 
& 1 & 2 & 3 & B & SE B & Beta \\
\hline (Constant) & & & & $* * * 17.80$ & .86 & \\
1. Instructional Design and Organization & 1.00 & & & $* * * .46$ & .07 & .14 \\
2. Directed Facilitation & $* * * .81$ & 1.00 & & $* * * .81$ & .03 & .67 \\
3. Gender & $* *-.05$ & $*_{-} .05$ & 1.00 & $*_{-} .79$ & .36 & -.03 \\
\hline
\end{tabular}

${ }^{*} \mathrm{p}<.05, * * \mathrm{p}<.01, * * * \mathrm{p}<.001$

Table 7. Correlation Coefficients, Unstandardized Beta, Standard Error, and Standard Beta of the Regression Model of Learning Community 


\section{DISCUSSION}

In this paper we have attempted to investigate the connection between students' sense of learning community as measured by Rovai's Classroom Community Scale and teaching presence as measured by indicators that reflect components in the Community of Inquiry Model as described by Garrison, Anderson, and their colleagues. We agree with a growing number of researchers that a sense of shared purpose, trust, support, and collaboration-i.e., a sense of community-is an essential element in the development of quality online learning environments in much the same way as it is in the development of high-quality traditional learning environments. We believe that online learning community may be established through effective instructional design and organization, the facilitation of productive discourse, and helpful direct instruction, all components of teaching presence as described by the Community of Inquiry Model. Our results raise a number of issues that warrant further discussion.

One of the purposes of this study was to establish the validity and reliability of an instrument that can be used to measure students' sense of teaching presence in their online courses. We developed such an instrument, and the results presented here have a number of implications. It appears that the initial threecomponent framework for teaching presence proposed under the Community of Inquiry Model may need to be revised. Our factor analysis indicates that a two-component model composed of instructional design and organization and directed facilitation emerges from the data. Seventy percent of the variance for the teaching presence construct can be accounted for by these two factors. These results suggest that the indicators identified in the Community of Inquiry Model that are meant to reflect direct instruction do not appear to reliably reveal a latent component of a teaching presence construct. Although we believe that direct instruction may be an important element of teaching both in traditional and online environments, the indicators used here do not cohere into a single component that may be interpreted as a discrete factor; instead, they contribute to another factor. Given that approximately twenty-five percent of the variance for the teaching presence construct is unaccounted for by the analysis presented here, two possibilities emerge: either we need better indicators for direct instruction in online environments to understand teaching presence more clearly and comprehensively, or direct instruction is not particularly necessary in online environments, and other factors are more important. The latter view reflects findings from some researchers of traditional environments [e.g., 39], especially when considering the efficacy of discourse facilitation relative to direct instruction in promoting learning and community. Additional research is needed to address these questions.

Another purpose of this study was to understand the relationship between students' recognition of teaching presence on the part of their instructor and their overall sense of learning community. Through regression analysis we attempted to determine how much of the variance in the Classroom Community Scale - the proxy we used to measure learning community - could be accounted for by students' sense of teaching presence. We sought to understand the proportion of the variance in students' senses of learning community that could be predicted by the teaching presence factors we identified through the initial factor analysis. We also wished to understand whether demographic characteristics contributed to students' sense of learning community. We found that, in descending order, student recognition of effective directed facilitation, instructional design and organization, and student gender each played a role in predicting their overall sense of learning community. These are discussed in more detail in the conclusions and recommendations sections below.

\section{CONCLUSIONS}

It appears from the analysis presented here that a number of conclusions can be made. The hypothesis that perceived teaching presence is associated with students' sense of learning community was supported. 
Survey respondents were more likely to report a stronger sense of learning community when they also reported that their instructors exhibited stronger "teaching presence" behaviors. In a general sense, when students reported effective instructional design and organization and "directed facilitation" of discourse, as defined by the teaching presence section of the instrument, they were more likely to report higher levels of learning community, as measured by the Classroom Community Scale. A majority of the variance in the scores for this measure of learning community can be explained by the students' sense of their instructors' teaching presence.

Directed facilitation on the part of the instructor contributes more to the equation than measures of effective instructional design and organization and gender differences do. This study reveals that a strong and active presence on the part of the instructor — one in which she or he actively guides the discourse-is related to students' sense of both connectedness and learning. This finding does not discount the importance of good instructional design and organization. Student who reported more effective instructional design and organization also reported higher levels of learning community; the contribution to the regression equation was simply not as great.

To understand matters from these results it is useful to recall the components of directed facilitation that contribute to students' sense of connectedness to course participants and to their sense of learning. These components include whether the students feel the instructor is drawing in participants, creating an accepting climate for learning, keeping students on track, and diagnosing misperceptions. Additionally when students feel their instructors are identifying areas of agreement and disagreement and helping to resolve these by looking for areas of consensus the students report higher levels of connectedness and learning. Further when students report that the instructor is reinforcing student contributions, injecting their own knowledge, and confirming student understanding, they are also more likely to report a better sense of learning community as measured by the Rovai instrument.

In addition to the directed facilitation outlined above, student perceptions of effective instructional design and organization also appear to matter in regards to a sense of connectedness and learning. The communication of time parameters, due dates, and deadlines contribute to learning community as do clear course goals, course topics, and instructions on how to effectively and appropriately participate in the course.

In addition to teaching presence behaviors, we examined student demographics as they relate to students' sense of community in the online learning environment. One variable that we thought might provide insight was course duration; however, we did not find evidence that courses that are of longer duration resulted in a better sense of learning community. Student characteristics that we thought might be of interest included age, gender, employment status, reason for taking the course online, physical distance from campus, and previous online learning experience. Brown [24] concluded that experienced students have more time to devote to community building than their newer counterparts and that novice online students require greater interaction with and support from online instructors. We did not find strong evidence to support these hypotheses in the present study, however. Although small differences were noted with regard to gender, the other demographic variables entered in the regression equation did not significantly contribute to the prediction for students' sense of learning community. This result may surprise some observers; it seems reasonable that at least some of these demographic variables might serve as proxies for important predictors of ability or desire to participate in a learning community. For example, full-time employment status might indicate that the student is busy or already a member of other communities and therefore less likely to recognize and feel part of a learning community in an online course. On the other hand, increased distance from campus might reasonably be interpreted as a measure of academic isolation and therefore associated with a desire for participation in a learning community. However, we did not find an indication of such associations here. Students' reports of their instructors' 
teaching presence behaviors far more clearly predicted their sense of online learning community.

Given the literature already available on the importance of a sense of community to student success, these findings have a number of implications for faculty development, online course design, and online instruction. These will be covered in the recommendations section below.

\section{RECOMMENDATIONS}

Given the documented link between a stronger sense of community and reduced attrition levels in face-toface instruction, the results reported here seem particularly promising. Because of ongoing concerns about higher attrition levels in online environments than in traditional environments, gaining an understanding of how to increase online students' sense of community is crucial. Several recommendations are warranted based on the results presented here. In light of the strong association between students' perceptions of teaching presence and their reports of levels of connectedness and learning, faculty development efforts should focus on helping new online instructors understand the roles associated with the establishment of teaching presence. It is common for faculty to receive training in online teaching that consists largely of a review of the course management system interface-the conventions for uploading or posting materials to the course, how to participate technically in online discussions, the technical creation of online assessments, etc. Although the technical components of online teaching are necessary, training in this area is insufficient for the goal of sustaining quality in the development of online learning environments. Gaining an understanding of the pedagogy of online learning is another necessary condition, and the framework of teaching presence and its components appear to be a useful mechanism for developing this understanding,

In previous research $[17,31]$ we reported on the importance of teaching presence and described how students of faculty who received training in teaching presence were significantly more likely to report higher levels of satisfaction and learning in their online courses. The multivariate analysis reported here suggests that effective instructional design and the skilled facilitation of discourse have a large positive effect on not only student satisfaction but students' sense of being connected with and supported by their instructor and fellow students in online environments. That the facilitation of discourse is the factor most strongly associated with students' sense of learning and community indicates that this skill should be emphasized and fostered through faculty development efforts. Applebee [40] suggests that the development of effective curriculum in traditional learning environments may be viewed as the creation of spaces for discourse: "a curriculum provides domains for conversation, and the conversation that takes place within those domains are the primary means of teaching and learning” (p. 37). It should not be surprising that the capacity to develop and sustain these conversations is also a crucial skill for online teaching and learning.

Course designs featuring abundant opportunity for discussion that is actively and publicly facilitated by the instructor seem to be warranted. Designs in which course goals and topics are clearly communicated, course learning activities are clearly explained, and time parameters are clearly documented are preferable. Furthermore, instructors should provide clear instructions on how to effectively participate in important course activities, such as online threaded discussion, and should offer guidelines on acceptable methods of interaction within such discussions. Helping students understand that online discussions may lead to misunderstanding and "flaming," and documenting policies on appropriate forms of interaction (netiquette) still appear relevant to supporting students’ sense of learning and community. 
It is important to students that instructors help to identify and resolve areas of agreement and disagreement on course topics and help the group to achieve a sense of consensus. It also seems clear that instructors in online courses need to draw in participants, keep students on task, and focus the course conversations on relevant issues. Furthermore, instructors should expand opportunities for learning by presenting content and questions and providing explanatory feedback that helps to confirm understanding. None of these recommendations should come as a great surprise, as they are also applicable to traditional and blended learning environments.

The finding that gender plays a small role in students' sense of learning community supports previous research and also requires additional study. Previously [41] we have reported similar small correlations indicating that women tend to report more learning, more satisfaction, fewer technical difficulties, and higher levels of interaction with their classmates and with faculty in online learning environments. The current finding adds to the list of positive outcomes that seem to be (weakly) associated with gender that arise when looking at data with large sample sizes. These findings are in alignment with those from other large-sample research [e.g., $42(n=1,244)$ ] indicating some indices of better performance on the part of women in online courses. Added to our previous finding this may point to a trend in which such results are not evident when examining smaller samples such as students enrolled in individual courses. Though practical implications may be slight [43], it would be worthwhile to make faculty in online environments aware that some evidence suggests that male students need greater support in the development of online learning communities. It would be useful as well to make students aware of the benefits and components of learning community, especially those who may have difficulty in seeing those benefits or forging interpersonal connections in online environments.

Additional research is needed to understand how the most highly rated instructors are developing and structuring online conversations. The strategies that are employed across different disciplines may vary, and understanding and sharing effective mechanisms for discourse facilitation across academic areas though faculty training efforts would assist the development of the online enterprise greatly.

Additional research is also needed to determine if the number of items in the present instrument may be reduced further without sacrificing the amount of variance for which it accounts. Initial analysis indicates that this may be possible-experimenting with other regression models suggests that at least five items in the teaching presence section may be removed without losing a significant amount of the variance for the learning community measure. Reducing the number of items may make this instrument less burdensome and therefore easier to administer, thus promoting its utility as a mechanism for assessment in other online programs. The CCI has also been revised since we designed this research and in now available in a shorter form that may be useful [44]. We will attempt to confirm this analysis in subsequent research.

These results, drawn from a relatively large sample size, may be considered a benchmark for other institutions seeking to develop high-quality online teaching and learning environments. The overall average scores that were reported here may be improved upon by helping faculty to "do more" of what appears to matter to students, i.e. where learners report higher levels of teaching presence behaviorsactive "directed facilitation" and effective instructional design and organization - they also report higher levels of learning community. Institutions can use these baseline scores and recommendations to begin to create learning environments that promote higher levels of connectedness and learning both online and offline. If the positive connection between student sense of community and higher retention rates applies to online learning-and there is little reason to doubt that it does-schools should also begin to see reduced levels of attrition. 


\section{REFERENCES}

1. Bransford, D., A. Brown, and R. Cocking, eds. How People Learn: Brain, Mind, Experience and School. Washington, DC: National Academies Press, 1999.

2. Johnson, D. W., R. T. Johnson, and K. Smith. Active Learning: Cooperation in the College Classroom. Edina, MN: Interaction Book Company, 1998.

3. Millis, B. and P. Cottell. Cooperative Learning for Higher Education Faculty. Westport, CT: American Council on Education/Oryx Press, 1998.

4. Scardamalia, M. and C. Bereiter. Computer support for knowledge-building communities. The Journal of the Learning Sciences 3 (3): 265-283, 1994.

5. Wenger, E. Communities of Practice: Learning, Meaning, and Identity. New York: Cambridge University Press, 1997.

6. Dede, C. The evolution of distance education: Emerging technologies and distributed learning. American Journal of Distance Education 10 (2): 4-36, 1996.

7. Rovai, A. P. A preliminary look at structural differences in sense of classroom community between higher education traditional and ALN courses. Journal of Asynchronous Learning Networks 6 (1): 41-56, 2002.

8. Rovai, A. P. Development of an instrument to measure classroom community. The Internet and Higher Education 5 (2002): 197-211.

9. Sergiovanni, T. J. Building Community in Schools. San Francisco: Jossey Bass, 1994.

10. Haythornthwaite, C., M. M. Kazmer, G. Robins, and S. Shoemaker. Community development among distance learners: Temporal and technological dimensions. Journal of Computer-Mediated Communications 6 (1): 2000. Online: http://jcmc.indiana.edu/vol6/issue1/haythornthwaite.html.

11. Morgan, C. K., and M. Tam. Unraveling the complexities of distance education student attrition. Distance Education 20 (1):96-108, 1999.

12. Carr, S. As distance education comes of age, the challenge is keeping the students. The Chronicle of Higher Education 46 (23): 39-41, 2000.

13. Bruffee, K. A. Collaborative Learning: Higher Education, Interdependence, and the Authority of Knowledge. Baltimore, MD: The Johns Hopkins University Press, 1993.

14. Walker, J., S. Wasserman, and B. Wellman. Statistical models for social support networks. In S. Wasserman and J. Galaskiewicz, (eds.) Advances in Social Network Analysis,, 53-78. Thousand Oaks, CA: Sage Publications, 1994.

15. Wellman, B. and M. Gulia. The network basis of social support: A network is more than the sum of its ties. In B. Wellman, (ed.) Networks in the Global Village, 83--18. Boulder, CO: Westview Press. 1994.

16. Garrison, D. R., T. Anderson, and W. Archer. Critical inquiry in a text-based environment: Computer conferencing in higher education. The Internet and Higher Education 11 (2): 1-14, 2000. Online: http://communitiesofinquiry.com/documents/CTinTextEnvFinal.pdf.

17. Shea, P., E. Fredericksen, A. Pickett, and W. Pelz. A preliminary investigation of teaching presence in the SUNY Learning Network. In J. Bourne and J.C. Moore, (eds.), Elements of Quality Online Education: Practice and Direction, 279-312. Needham, MA: Sloan Consortium, 2003.

18. Jiang, M., and E. Ting. A study of factors influencing students' perceived learning in a web-based course environment. International Journal of Educational Telecommunications 6 (4): 317-338, 2000.

19. Swan, K., and P. Shea. Social presence and the development of virtual learning communities. In S. Hiltz and R. Goldman, Learning Together Online: Research on Asynchronous Learning Networks, 239-260. Mahwah, NJ: Lawrence Erlbaum Associates, 2005.

20. Richardson, J. and K. Swan. Examination of social presence in online learning: Students' perceived learning and satisfaction. Journal of Asynchronous Learning Networks 7 (1): 68-88, 2003. 
21. Dzuiban, C., P. Shea, and J. B. Arbaugh. Faculty roles and satisfaction in ALNs. In S. Hiltz and R. Goldman, Learning Together Online: Research on Asynchronous Learning Networks, 169-190. Mahwah, NJ: Lawrence Erlbaum Associates, 2005.

22. Swan, K., P. Shea, E. Fredericksen, A. Pickett, W. Pelz, and G. Maher. Building knowledge building communities: Consistency, contact and communication in the virtual classroom. Journal of Educational Computing Research 23 (4): 389-413, 2000.

23. Picciano, A. G. Beyond student perceptions: Issues of interaction, presence, and performance in an online course. Journal of Asynchronous Learning Networks 6 (1); 21-40, 2002.

24. Brown, R. The process of community building in distance learning classes. Journal of Asynchronous Learning Networks 5 (2): 18-35, 2001.

25. Shea, P. J., K. Swan, E. E. Fredericksen, and A. M. Pickett. Student satisfaction and reported learning in the SUNY Learning Network. In J. Bourne and J. C. Moore, (ed.) Elements of Quality Online Education, Volume 3 in the Sloan-C Series, 145-155. Needham, MA: Sloan Consortium, 2001.

26. Shea, P., E. Fredericksen, A. Pickett, and W. Pelz. Faculty development, student satisfaction, and reported learning in the SUNY Learning Network. In T. Duffy and J. Kirkley, (eds.) Learnercentered Theory and Practice in Distance Education, 343-377. Mahwah, NJ: Lawrence Erlbaum Associates, 2003.

27. Chickering, A. W. and A. F. Gamson. Seven Principles for Good Practice in Undergraduate Education. Racine, WI: The Johnson Foundation, Inc./Wingspread, 1987.

28. Arbaugh, J. B. and S. C. Hornik. Predictors of perceived learning and satisfaction in web-based MBA courses: A test and extension of Chickering and Gamson's (1987) 7 principles of good practice in education. Presented at the $33^{\text {rd }}$ Annual Meeting of the Decision Sciences Institute, San Diego, CA. Online: http://www.sbaer.uca.edu/research/dsi/2002/papers/176.pdf.

29. Anderson, T., L. Rourke, D. R. Garrison, and W. Archer. Assessing teaching presence in a computer conferencing context. Journal of Asynchronous Learning Networks 5 (2): 1-17, 2001.

30. Berge, S.L. Facilitating computer conferencing: Recommendations from the field. Educational Technology 15 (1): 22-30, 1995.

31. Shea, P., A. Pickett, and W. Pelz. A follow-up investigation of teaching presence in the SUNY Learning Network. Journal of Asynchronous Learning Networks 7 (2): 61-80, 2003.

32. Cattan, M., M. White, J. Bond, A. Learmouth. Preventing social isolation and loneliness among older people: A systematic review of health promotion interventions. Ageing and Society 25 (1): 4150, 2005.

33. Yeh, S. J. and K. L. Sing. Living alone, social support and feeling lonely among the elderly. Social Behavior and Personality: An International Journal 32 (2): 129-139, 2004.

34. Vandervoort, D. Social isolation and gender. Current Psychology 19 (3): 229-23, 2000.

35. Shumaker, S. and D. Hill. Gender differences in social support and physical health. Health Psychology 10 (2): 102-111, 1991.

36. Bostock, S. and W. Lizhi. Gender in students' online discussions. Innovations in Education and Teaching International 42 (1): 73-86, 2005.

37. Goldstein, J. and P. Sadhana. The brink of change: Gender in technology-rich collaborative learning environments. Journal of Science Education and Technology 13 (4): 505-523, 2004.

38. Tabachnick, B. G. and L. S. Fidell. Using Multivariate Statistics.. Boston, MA: Pearson Allyn \& Bacon, 2001.

39. Tharp, R. and R. Gallimore. Rousing Minds to Life: Teaching, Learning, and Schooling in Social Context. New York: Cambridge University Press, 1988.

40. Applebee, A. Curriculum as Conversation. Chicago, IL: University of Chicago Press, 1996.

41. Shea, P., E. Fredericksen, A. Pickett, W. Pelz, and K. Swan. Measures of learning effectiveness in the SUNY Learning Network. In J. Bourne and J.C. Moore, (eds.) Online Education: Learning Effectiveness, Faculty Satisfaction, and Cost Effectiveness 2, 31-54. Needham, MA: Sloan Consortium, 2001. 
42. Benbunan-Fich, R. and S. R. Hiltz. Correlates of effectiveness of learning networks: The effects of course level, course type, and gender on outcomes. Paper presented at the $35^{\text {th }}$ Annual Hawaii International Conference on System Sciences, Big Island, HI, 2002. Online: http://csdl2.computer.org/comp/proceedings/hicss/2002/1435/01/14350005b.pdf.

43. Astleiner, H. and R. Steinberg. Are there gender differences in web-based learning? An integrated model and related effect sizes. AACE Journal 13 (1): 47-63, 2005.

44. Rovai, A. P., M. J. Wighting, and R. Lucking. The Classroom and School Community Inventory: Development, refinement, and validation of a self-report measure for educational research. The Internet and Higher Education 7 (4): 263-280, 2004.

\section{AUTHOR BIOGRAPHIES}

Peter Shea is a member of the faculty in the Department of Educational Theory and Practice at University at Albany, State University of New York, where he has taught at the graduate level both online and in the classroom. He has a joint appointment in the College of Computing and Information. Previously he was the director of the SUNY Learning Network, the award-winning online education system for the State University of New York. Dr. Shea has also served as manager of the SUNY Teaching, Learning, and Technology Program and as project director for SUNY's participation in the Multimedia Educational Resource for Learning and Online Teaching (MERLOT), an international collaboration for peer review of discipline-specific online learning resources. He is also member of the USNY Technology Policy Council.

His research focuses on the student and faculty experience in technology-mediated teaching and learning, most recently on the topics of teaching presence and community in asynchronous learning networks. He is the author of many articles and several book chapters on the topic of online learning, co-author of The Successful Distance Learning Student (Thomson-Wadsworth), and a contributor to the new book Learning Together Online: Research on Asynchronous Learning Networks (Lawrence Erlbaum). He is a co-recipient of several awards, including the EDUCAUSE Award for Systemic Progress in Teaching and Learning for the State University of New York, and Sloan Consortium Awards for Excellence in Faculty Development and Asynchronous Learning Networks Programs. He is a member of the American Educational Research Association and the editorial board for the Journal of Asynchronous Learning Networks. His research has appeared in the Journal of Educational Computing Research, The International Review of Research in Open and Distance Learning, and the Journal of Asynchronous Learning Networks.

Karen Swan is research professor in the Research Center for Educational Technology at Kent State University and the Learning Effectiveness Pillar Editor for the Sloan Consortium. Dr. Swan's research is in the general area of media and learning. She has published and presented nationally and internationally in the specific areas of programming and problem solving, computer-assisted instruction, hypermedia design, technology and literacy, and technology professional development.

Her current research focuses on student learning in ubiquitous computing environments and on online learning - in particular, on interactivity, social presence, and interface issues. Dr. Swan has authored several hypermedia programs as well as three online courses and has co-edited a book on Social Learning From Broadcast Television. She is the special issues editor for the Journal of Educational Computing Research and a member of the national advisory board of the Ubiquitous Computing Evaluation Consortium. 
Alexandra M. Pickett is the assistant director of the SUNY Learning Network (SLN), the asynchronous learning network for the State University of New York. A pioneer in instructional design and faculty training for asynchronous web-based teaching and learning environments, Ms. Pickett has since 1994 led the development of the instructional design methods, support services, and resources used by SLN to support the creation and delivery of fully online courses by SUNY campuses and faculty. One of the original SLN design team members, she co-designed the course management software and authored the four-stage faculty development process and seven-step course design process used by the network. Her comprehensive approach to faculty development includes an online faculty resource and information gateway, an online conference for all faculty with the opportunity to observe a wide variety of online courses, a series of workshops for new faculty, instructional design sessions for returning faculty looking to improve their courses, a developer's handbook, a course template, a faculty HelpDesk, online mechanisms for faculty evaluation of SLN services, and an assigned instructional design partner. Today, working with fifty-six of the sixty-four SUNY institutions, she has directly supported or coordinated the development of more than 1,500 SUNY faculty and their web-delivered courses. Her research interests are in faculty satisfaction and the effective instructional design of online courses, and student satisfaction and perceived learning. She has co-authored a number of studies on these topics and has published and presented the results both nationally and internationally. Visit http://SLN.suny.edu/developer and http://SLN.suny.edu/conference.

\section{APPENDIX A}

Comparison of Demographic Data of Sample to Those of Cohort Population

\begin{tabular}{|c|c|c|c|c|}
\hline & $\begin{array}{c}\text { Sample } \\
\text { Frequency }\end{array}$ & $\begin{array}{l}\text { Sample } \\
\text { Percent }\end{array}$ & $\begin{array}{l}\text { Population } \\
\text { Frequency }\end{array}$ & $\begin{array}{c}\text { Population } \\
\text { Percent }\end{array}$ \\
\hline \multicolumn{5}{|l|}{ Gender } \\
\hline 1 Female & 1,689 & 73.0 & 7,995 & 68.0 \\
\hline 2 Male & 625 & 27.0 & 3,794 & 32.0 \\
\hline \multicolumn{5}{|l|}{ Age } \\
\hline $115-24$ & 916 & 39.6 & 4,918 & 41.7 \\
\hline $225-34$ & 640 & 27.7 & 3,540 & 30.0 \\
\hline $335-44$ & 506 & 21.9 & 2,092 & 17.7 \\
\hline $445-54$ & 217 & 9.4 & 1,069 & 9.1 \\
\hline $555-64$ & 34 & 1.5 & 157 & 1.3 \\
\hline $665+$ & 1 & .0 & 14 & .12 \\
\hline \multicolumn{5}{|l|}{ Registration status } \\
\hline 1 Full-time & 1,010 & 43.6 & 5,873 & 49.8 \\
\hline 2 Part-time & 1,304 & 56.4 & 5,917 & 50.2 \\
\hline \multicolumn{5}{|l|}{ Employment Status } \\
\hline 1 Part-time & 609 & 26.3 & 3,683 & 31.2 \\
\hline 2 Full-time & 1,268 & 54.8 & 5,882 & 49.9 \\
\hline 3 Not employed & 437 & 18.9 & 2,224 & 18.9 \\
\hline \multicolumn{5}{|l|}{ Distance from campus } \\
\hline 1 On campus & 23 & 1.0 & 176 & 1.5 \\
\hline $2<30$ minutes & 852 & 36.8 & 5,006 & 42.5 \\
\hline
\end{tabular}


Developing Learning Community in Online Asynchronous College Courses:

The Role of Teaching Presence

330 minutes to 1 hour

41 hour to 2 hours

5 More than 2 hours
510

292

637

Modem type

128.8

233.6

356

4 Cable Modem

5 LAN

6 DSL

7 ISDN

8 Don't know

43

14

372

948

193

333

5

406
Why Online

1 Conflict with personal schedule

2 Course not offered on campus/schedule conflict

3 Distance or lack of transportation

4 Family responsibilities

5 Interest in technology/internet

6 Other

Duration of course in days

1 Less than 65

2 More than 66
820

412

378

441

73

190

1,186

1,128
22.0

2,633

12.6

27.5

1.9

0.6

16.1

41.0

8.3

14.4

0.2

17.5

22.3

11.6

22.1

2,609

203

1.7

54

0.5

15.0

42.2

7.9

13.8

.3

18.6

2,189

4,887

41.6

17.8

2,000

17.0

16.3

1,642

13.9

19.1

1,884

16.0

493

4.2

884

7.5

\section{APPENDIX B}

Online Teaching and Learning Questionnaire

\section{Course}

1. Online Experience

This is my first online course.

I have taken one online course before.

I have taken two online courses before.

I have taken three or more online courses before.

1A. Web-Enhanced Course Experience*

This is my first course with online components.

I have taken one online course or course with online components before.

I have taken two online courses or courses with online components before.

I have taken three or more online courses or courses with online components before. 
2. Overall, I was satisfied with this course.

Strongly Agree

Agree

Neutral

Disagree

Strongly Disagree

3. Overall, I learned a great deal in this course.

\section{Learning Community}

DIRECTIONS: Below you will see a series of statements concerning a specific course or program you are presently taking or recently completed. Read each statement carefully and select the choice that comes closest to indicating how you feel about the course or program. There are no correct or incorrect responses. If you neither agree nor disagree with a statement or are uncertain, select the neutral choice. Do not spend too much time on any one statement, but give the response that seems to describe how you feel. Please respond to all items in this section.

4. I feel that students in this course care about each other.

5. I feel that I am encouraged to ask questions.

6. I feel connected to others in this course.

7. I feel that it is hard to get help when I have a question.

8. I do not feel a spirit of community.

9. I feel that I receive timely feedback.

10. I feel that this course is like a family.

11. I feel uneasy exposing gaps in my understanding.

12. I feel isolated in this course.

13. I feel reluctant to speak openly.

14. I trust others in this course.

15. I feel that this course results in only modest learning.

16. I feel that I can rely on others in this course. 
17. I feel that other students do not help me learn.

18. I feel that members of this course depend on me.

19. I feel that I am given ample opportunities to learn.

20. I feel uncertain about others in this course.

21. I feel that my educational needs are not being met.

22. I feel confident that others will support me.

23. I feel that this course does not promote a desire to learn.

\section{Instructional Design and Organization}

\section{Setting the curriculum}

24. Overall, the instructor for this course clearly communicated important course goals (for example, provided documentation on course learning objectives).

25. Overall, the instructor for this course clearly communicated important course topics (for example, provided a clear and accurate course overview).

\section{Designing methods}

26. Overall, the instructor for this course provided clear instructions on how to participate in course learning activities (for example, provided clear instructions on how to complete course assignments successfully).

\section{Establishing time parameters}

27. Overall, the instructor for this course clearly communicated important due dates and time frames for learning activities that helped me keep pace with this course (for example, provided a clear and accurate course schedule, due dates, etc.)

\section{Utilizing the medium effectively}

28. Overall, the instructor for this course helped me take advantage of the online environment in a way that assisted my learning (for example, provided clear instructions on how to participate in online discussion forums).

\section{Establishing netiquette}

29. Overall, the instructor for this course helped students understand and practice the kinds of behaviors acceptable in online learning environments (for example, provided documentation on netiquette, i.e., polite forms of online interaction). 


\section{Facilitating Discourse}

\section{Identifying areas of agreement/disagreement}

30. Overall, the instructor for this course was helpful in identifying areas of agreement and disagreement on course topics that assisted me to learn.

\section{Seeking to reach consensus}

31. Overall, the instructor for this course was helpful in guiding the class towards understanding course topics in a way that assisted me to learn.

\section{Reinforcing student contributions}

32. Overall, the instructor in this course acknowledged student participation in the course (for example, replied in a positive, encouraging manner to student submissions)

\section{Setting climate for learning}

33. Overall, the instructor for this course encouraged students to explore new concepts in this course (for example, encouraged "thinking out loud" or the exploration of new ideas)

Drawing in participants, prompting discussion

34. Overall, the instructor for this course helped keep students engaged and participating in productive dialogue.

Assessing the efficacy of the process

35. Overall, the instructor for this course helped keep the participants on task in a way that assisted my learning.

\section{Direct Instruction}

Presenting content/questions

36. Overall, the instructor for this course presented content or questions that helped me learn.

Focusing the discussion on specific issues

37. Overall, the instructor for this course focused discussion on relevant issues in a way that helped me learn.

\section{Confirming understanding}

38. Overall, the instructor for this course provided explanatory feedback that helped me learn (for example, responded helpfully to discussion comments or course assignments).

\section{Diagnosing misconceptions}

39. Overall, the instructor for this course helped me to revise my thinking (for example, correct misunderstandings) in a way that assisted my learning.

Injecting knowledge from diverse sources

40. Overall, the instructor for this course provided useful information from a variety of sources that 
assisted my learning (for example, references to articles, textbooks, personal experiences, or links to relevant external websites).

\section{Learning Online}

DIRECTIONS: If you took a completely online course, please answer question 41. If you took a classroom-based course with online components, skip to question 41A.*

41. Think of a similar course you have taken in the classroom. Compared to that course (i.e., a course that was not online) how would you rate your level of learning in this course?

I learned more in the classroom than in this online course.

I learned about the same in this online course as I did in the classroom.

I learned more in this online course than I did in the classroom.

41A. Think of a similar course you have taken in the classroom that did not contain any online components. Compared to that course, how would you rate your level of learning in this course?

The online components helped me learn, so I learned more in this course.

The online components had no impact on my learning; I learned about the same in this course.

The online components had a negative impact on my learning; I learned less in this course.

Not applicable-I was unaware that this course used online components, or I did not go to the course website.

DIRECTIONS: If you took a completely online course, please answer question 42. If you took a classroom-based course with online components, skip to question 42A.*

42. Based on your experience, would you consider taking other online courses in the future?

Yes, as many as possible.

Yes, some additional courses.

Undecided.

No, unless absolutely necessary

No.

42A. Based on your experience in this course, would you consider taking other courses with online components in the future?

Yes, as many as possible.

Yes, some additional courses.

Undecided.

No, unless absolutely necessary

No.

* Participants in the study described here were drawn solely from the sample of completely online learners identified through demographics collected by the researchers. 